\title{
Comparison of three methods of determining oxygen consumption and resting energy expenditure
}

\author{
BRIAN J. WALSH, DO \\ THOMAS F. MORLEY, DO
}

\begin{abstract}
Resting energy expenditure (REE) in intensive care unit patients was evaluated by three methods--indirect calorimetry (REE-IC), Fick equation (REEF), and estimation from the Harris-Benedict equation (REE-HB). The mean REE-IC and REE-F values did not differ significantly. However, both values were significantly higher than the REE-HB. The present study indicates that a reasonably accurate estimate of the REE can be obtained from data available by Swan-Ganz catheterization. The Fick method is technically simpler to perform and less expensive than indirect calorimetry. The invasive nature of Swan-Ganz catheterization is a major disadvantage. However, right-sided heart catheterization frequently is required for the management of intensive care unit patients. For them, REE-F appears to be a reasonable alternative.
\end{abstract}

Energy requirements for intensive care unit patients are difficult to predict. The detrimental effects of malnutrition, including delayed wound healing and altered immunity, are well documented..$^{1-3}$ Conversely, the administration of calories in excess of metabolic requirements may be harmful. This is especially true of excess glucose loads in patients with respiratory compromise. ${ }^{4,5}$ These data suggest that an accurate method for the assessment of energy requirements is needed for patients in the intensive care setting.
The classic method for estimating the resting energy expenditure (REE) is the Harris-Benedict (HB) equation, ${ }^{6}$ which relates the patient's age, height, weight, and sex to the REE. Although the REE-HB equation provides a reasonable estimate in normal adults, REE is more variable in intensively ill patients. ${ }^{7}$ Some investigators have attempted to improve the ability of the HB equation to predict the REE by applying "stress factors" to the calculation. ${ }^{8}$ Depending upon the assumed level of surgical or medical stress, these factors increase the HB estimate of the REE by $10 \%$ to $50 \%$. However, the value of using these stress factors is limited by the wide variability among individual patients..$^{9,10}$

Indirect calorimetry (IC) allows the measurement of oxygen consumption $\left(\mathrm{VO}_{2}-\mathrm{IC}\right)$ from the difference in oxygen concentration in inspired and expired air. The REE-IC can be calculated as the product of $\mathrm{VO}_{2}-\mathrm{IC}$ and the caloric value of oxygen. However, this method is expensive, often not readily available, and technically demanding. In patients who require mechanical ventilation, fluctuations in inspired oxygen concentration may make determination of $\mathrm{VO}_{2}-\mathrm{IC}$ difficult, unless external blenders or tanks of known oxygen concentration are used..$^{9,11}$

Recently, Liggett and coworkers ${ }^{12}$ have demonstrated that $\mathrm{VO}_{2}$ can be measured accurately in patients who have Swan-Ganz catheters in place by application of the Fick equation. It also was shown that REE could be estimated from the $\mathrm{VO}_{2}$. The present study was undertaken to compare the REE determined by the Fick method (REE-F) to that determined by REE-IC or REE-HB in intensive care unit patients. 


\section{Materials and methods}

Seven patients were studied in the intensive care units of the Kennedy Memorial Hospitals, University Medical Center, Stratford, NJ. Six patients were ventilator-dependent and one was breathing room air. One patient was studied on three occasions over a three-week period, four patients were studied twice (each approximately 24 hours apart), and two patients were studied once. All patients had thermodilution catheters in place for established clinical indications.

Metabolic measurements were made with an automated system, the Gould 9000 aerobic measurement system. This equipment uses paramagnetic oxygen and infrared carbon dioxide analyzers. The analyzers were connected in line with the inspiratory and expiratory circuits of the ventilator, with one-way values separating inspiratory from expiratory flow. The patient breathing room air was studied with mouthpiece and noseclip. Inspired oxygen concentration was controlled with the internal blenders of the Puritan-Bennett 7200 ventilator. An external blender was used for the patient on the MA-1 ventilator. External blenders were used for the other six patients. Inspired oxygen concentration varied from $21 \%$ to $70 \%$.

Metabolic measurements were made just before the performance of routine morning arterial and mixed venous blood gas sampling and thermodilution cardiac output determination. Expired gases were collected until stable readings were obtained. A minimum of 10 minutes of $\mathrm{VO}_{2}-\mathrm{IC}$ readings were averaged for the calculation of REE-IC. Each patient's nutritional support was continued if total parenteral or continuous enteral nutrition was being received. Patients who were eating or receiving bolus feeds were not studied within two hours of being fed.

A thermodilution cardiac output computer was used. ${ }^{13}$ All measurements were made with $10 \mathrm{cc}$ of iced $5 \%$ dextrose. Three readings within $10 \%$ of each other were averaged. Arterial blood samples were obtained from arterial catheter when present, or by arterial puncture. Mixed venous blood was obtained by aspiration from the distal pulmonary artery port. Oxygen tensions from both samples were measured by tonometry, and saturation was calculated from standard curves. Hemoglobin concentrations were determined using a Coulter counter.

Oxygen consumption was calculated by modification of the Fick equation in the following manner:

$$
\mathrm{VO}_{2}-\mathrm{F}=\left(\mathrm{CaO}_{2}-\mathrm{CvO}_{2}\right) \times \mathrm{CO}
$$

where $\mathrm{VO}_{2}-\mathrm{F}=$ oxygen consumption (cc/min), $\mathrm{CaO}_{2}=$ arterial oxygen content (volume \%), $\mathrm{CvO}_{2}$ $=$ mixed venous oxygen content (volume \%), and $\mathrm{CO}=$ cardiac output $(\mathrm{L} / \mathrm{min})$.

This equation can be transformed to:

$$
\mathrm{VO}_{2}-\mathrm{F}=\mathrm{CO} \times 1.36 \times 10 \times \mathrm{Hb} \times\left(\mathrm{SaO}_{2}-\mathrm{SvO}_{2}\right)
$$

where $1.36=$ the cc of oxygen bound per $g$ of hemoglobin, $\mathrm{Hb}=$ hemoglobin concentration $(\mathrm{g} / \mathrm{dL})$, and $\mathrm{SaO}_{2}$ and $\mathrm{SvO}_{2}$ are the arterial and mixed venous oxygen saturations (expressed as decimals).

Using Liggett and coworkers' ${ }^{12}$ assumption that the caloric value of oxygen is $4.86 \mathrm{kcal} / \mathrm{L}$ at a respiratory quotient of 0.85 , the REE-F can be expressed as:

$$
\mathrm{REE}-\mathrm{F}=\mathrm{VO}_{2}-\mathrm{F} \times 0.00486 \times 1440
$$

By substituting in equation 2:

$$
\mathrm{REE}-\mathrm{F}(\mathrm{kcal} / \mathrm{d})=\mathrm{CO} \times \mathrm{Hb} \times\left(\mathrm{SaO}_{2}-\mathrm{SvO}_{2}\right) \times 95.18
$$

The following equations were used to determine the basal metabolic rate by REE-HB:

$$
\begin{gathered}
\text { Males }=66+13.7 \mathrm{~W}+5 \mathrm{H}-6.8 \mathrm{~A} \\
\text { Females }=655+9.6 \mathrm{~W}+1.8 \mathrm{H}-4.7 \mathrm{~A}
\end{gathered}
$$

where $\mathrm{W}$ = weight in $\mathrm{kg}, \mathrm{H}=$ height in $\mathrm{cm}$, and $\mathrm{A}=$ age in years.

Some patients had more than one measurement of $\mathrm{VO}_{2}$. To eliminate repeated measures from statistical analysis, average values were obtained for each study parameter in patients who were studied more than once. The mean values for each group of study parameters were compared by the ANOVA procedure. Duncan's multiple range test was performed to determine which mean values were significantly different at an $\alpha$ value of 0.05 .

\section{Results}

Five men and two women were studied. All except one were being ventilated mechanically. Average age was $59.7 \pm 12.6(\mathrm{SD})$ years. The underlying diseases of the patients are outlined in Table 1.

The mean $\mathrm{VO}_{2}-\mathrm{IC}$ was $290 \pm 24(\mathrm{SEM}) \mathrm{cc} / \mathrm{min}$, and the mean $\mathrm{VO}_{2}-\mathrm{F}$ was $307 \pm 39(\mathrm{SEM}) \mathrm{cc} / \mathrm{min}$. These values were not significantly different when compared by ANOVA. The mean REE-IC, REE-F, and REE-HB were compared by ANOVA and were found to be significantly different $(P=0.02)$.

Duncan's multiple range test was performed to determine which groups were significantly different at an $\alpha$ value of 0.05 . This analysis revealed that the mean REE-IC and mean REE-F were not 


\begin{tabular}{|c|c|c|c|}
\hline $\begin{array}{l}\text { Age } \\
(\mathrm{yr})\end{array}$ & Sex & Ventilator & Diagnosis \\
\hline 63 & F & PB- $7200^{*}$ & $\begin{array}{l}\text { Acute myocardial infarction, } \\
\text { congestive heart failure }\end{array}$ \\
\hline 72 & M & MA- $1 \dagger$ & $\begin{array}{l}\text { Acute myocardial infarction, } \\
\text { cardiogenic shock }\end{array}$ \\
\hline 71 & M & PB-7200 & $\begin{array}{l}\text { Emergency aortic aneurysm, } \\
\text { acute renal failure, } \\
\text { pulmonary edema }\end{array}$ \\
\hline 72 & M & PB-7200 & $\begin{array}{l}\text { Subarachnoid hemorrhage, } \\
\text { pulmonary edema }\end{array}$ \\
\hline 48 & $\mathrm{~F}$ & PB-7200 & $\begin{array}{l}\text { Pulmonary contusion, } \\
\text { hip fracture }\end{array}$ \\
\hline 45 & M & PB-7200 & $\begin{array}{l}\text { Gram-negative sepsis, } \\
\text { adult respiratory distress } \\
\text { syndrome }\end{array}$ \\
\hline 47 & M & None & $\begin{array}{l}\text { Infected bronchiectasis, } \\
\text { chronic bronchitis }\end{array}$ \\
\hline \multicolumn{4}{|c|}{$\begin{array}{l}\text { *Puritan Bennett model } 7200 \text { ventilator } \\
\text { +Bennett model MA-1 ventilator }\end{array}$} \\
\hline
\end{tabular}

\begin{tabular}{|c|c|c|}
\hline Method & $\begin{array}{c}\text { Mean } \\
(\mathrm{kcal} / \mathrm{d})\end{array}$ & $\begin{array}{c}\text { SE } \\
\text { of mean }\end{array}$ \\
\hline REE-IC* & 2,000 & 270 \\
\hline REE-F* & 2,154 & 186 \\
\hline REE-HB $†$ & 1,581 & 121 \\
\hline \multicolumn{3}{|c|}{$\begin{array}{l}\text { * Means are not significantly different by Duncan's multiple } \\
\text { range test. } \\
\text { † Mean is significantly different by Duncan's multiple range } \\
\text { test. }\end{array}$} \\
\hline
\end{tabular}

significantly different (Table 2). However, both of these values were significantly higher than the mean REE-HB.

A reasonable correlation coefficient was achieved between REE-IC and REE-F when all 13 data points were used for analysis (Fig 1). If the averaged data for each patient were used, the Pearson's correlation coefficient was 0.88 .

The respiratory quotient varied from 0.70 to 1.09 , with a mean value of 0.81 . The mean variation in the inspired oxygen concentration was $0.9 \%$, with a range of $0.1 \%$ to $1.9 \%$.

\section{Discussion}

Our data demonstrate that REE can be estimated accurately with information provided from SwanGanz catheterization. Although our sample size was small, we believe that our patients represented a reasonable cross-section of intensive care unit patients. Our results are in agreement with those of Liggett and coworkers. ${ }^{12}$ However, their mean difference between REE-F and REE-IC was only 35 kcal $v 97 \mathrm{kcal}$ in our study. The facts that those authors used fixed oxygen concentrations from tanks and did not study patients on oxygen concentrations above $50 \%$ may account for their lesser variability. It appears that the blenders used in our study provide reasonably stable inspired oxygen concentrations $( \pm 1 \%)$ for IC.

Levinson and associates ${ }^{14}$ studied 29 mechanically ventilated patients and compared IC to thermodilution cardiac output for the determination of $\mathrm{VO}_{2}$. These investigators found a good correlation between the two methods, but $\mathrm{VO}_{2}-\mathrm{IC}$ was consistently $15 \%$ higher than $\mathrm{VO}_{2}-\mathrm{F}$. We observed a similar correlation coefficient but did not find any consistent difference between $\mathrm{VO}_{2}-\mathrm{IC}$ and $\mathrm{VO}_{2}-\mathrm{F}$.

The calculation of REE from $\mathrm{VO}_{2}-\mathrm{F}$ assumes that the respiratory quotient (RQ) is equal to 0.85 . Although the caloric value of oxygen actually varies with $R Q$, over the $R Q$ range of 0.7 to 1.0 , the error introduced into the calculated REE-F would be no more than $3.5 \%$. With this stipulation in mind, the conversion of $\mathrm{VO}_{2}-\mathrm{F}$ to REE-F seems justifiable. In addition, the mean RQ calculated by IC was 0.81 , which was fairly close to the assumed value.

Beside the REE-HB, other equations are available to estimate REE. ${ }^{15-17}$ Authors with a large experience in IC have suggested that it is not possible to be sure to which patients these equations apply. ${ }^{9}$ In our intensive care unit patients, REE-

\section{RESTING ENERGY EXPENDITURE FICK vs IC (Kcal/day)}

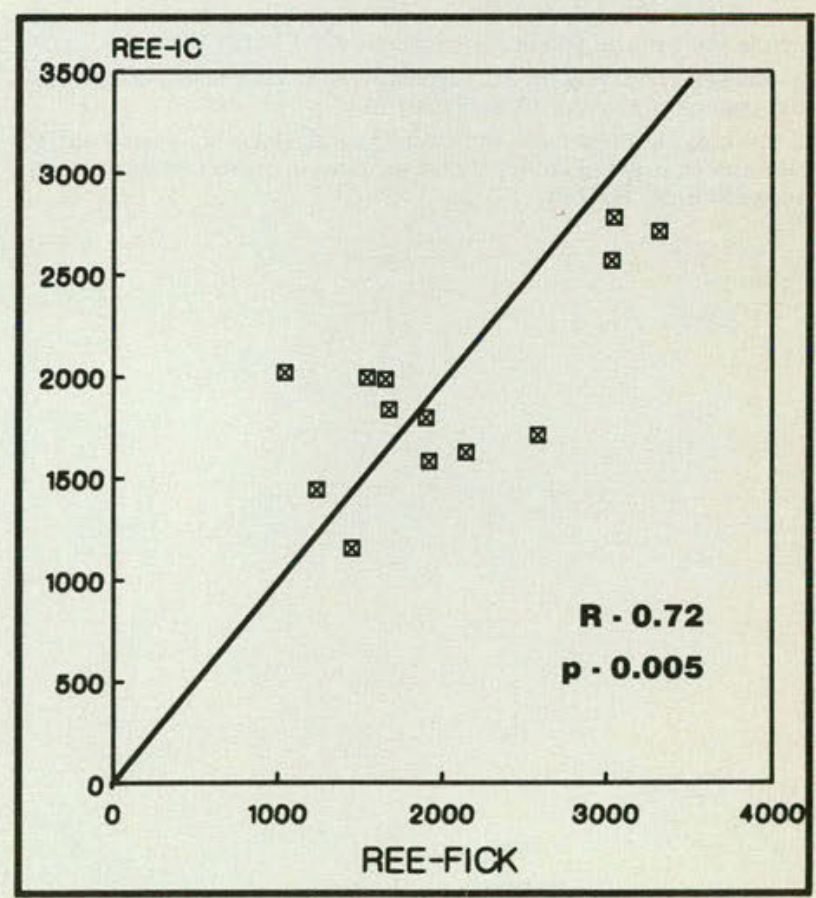

Fig 1. Resting energy expenditure estimates - Fick $\mathrm{v}$ indirect calorimetry methods. 
HB was significantly lower than the REE-IC and REE-F. Damask and coauthors ${ }^{10}$ have suggested that the more severely ill patients are, the less likely their prediction equations are to correlate with measured REE. We chose not to apply these so-called stress factors to our HB estimates; even if we had, there was wide variation between individuals. It appears that a stress factor of 1.2 to 1.3 times the group average REE-HB would have approximated the group average REE-F or REE-IC, but the range was from $0.8 \mathrm{REE}-\mathrm{HB}$ to $1.7 \mathrm{REE}$ $\mathrm{HB}$ for individual patients.

\section{Conclusions}

The Swan-Ganz catheter seems to have another important use in the intensive care setting. REE is easily and accurately estimated with the data it provides. It requires no more than the routine daily blood testing performed for other purposes. Serial measurements, even daily measurements, become practical with this method.

If a personal computer or programmable calculator is available, REE can be calculated at the bedside. Finally, calculating REE from the Fick equation is considerably less expensive and requires less technical expertise than IC. It also makes REE values available to centers without IC equipment.

\section{Jacqui Cater performed the statistical analysis for this study.}

1. Mullen JL, Gertner MH, Buzyby GP, et al: Implications of malnutrition in the surgical patient. Arch Surg 1979;114:121-125.

2. MacLean LD, Meakins JL, Taguchi K, et al: Host resistance in sepsis and trauma. Ann Surg 1975;182:207-217.

3. Meakins JL, Pietsch JB, Bubenick O, et al: Delayed hypersensitivity indicator of acquired failure of host defenses in sepsis and trauma. Ann Surg 1977;186:241-250.
4. Askanazi J, Carpentier YA, Elwyn DH, et al: Influence of total parenteral nutrition on fuel utilization in injury and sepsis. Ann Surg 1980;191:40-46.

5. Askanazi J, Rosenbaum SH, Hyman AI, et al: Respiratory changes induced by the large glucose loads of total parenteral nutrition. JAMA 1980;243:1444-1447.

6. Harris JA, Benedict FG: Standard Basal Metabolism Constants For Physiologists And Clinicians: A Biometric Study Of Basal Metabolism In Man. Philadelphia, JB Lippincott, 1919, p223.

7. Weissman C, Kemper M, Askanazi J, et al: Resting metabolic rate of the critically ill patient: Measured versus predicted. Anesthesiology $1986 ; 64: 673$

8. Long CL, Schafell CW, Blakemore WS, et al: A continuous analyzer for monitoring respiratory gases and expiratory radioactivity in clinical studies. Metabolism 1979;28:320-326.

9. Feurer ID, Mullen JL: Measurement of energy expenditure, in Rombeau JL, Caldwell MD, (eds): Parenteral Nutrition. Philadelphia, W.B. Saunders $\mathrm{Co}, 1986$.

10. Damask MC, Schwarz Y, Weissman C: Energy measurements and requirements of critically ill patients. Crit Care Clin 1987;3:71-96,

11. Browning JA, Linberg SE, Turney SZ, et al: The effects of fluctuating $\mathrm{FIO}_{2}$ on metabolic measurements in mechanically ventilated patients. Crit Care Med 1982;10:82-85.

12. Liggett SB, St John RE, Lefrak SS: Determination of resting energy expenditure utilizing the thermodilution pulmonary artery catheter. Chest 1987;91:562-566.

13. Ganz W: A new technique for measurement of cardiac output by thermodilution in man. Am J Cardiol 1971;27:392-396.

14. Levinson MR, Groeger JS, Miodownik S, et al: Indirect calorimetry in mechanically ventilated patients. Crit Care Med 1987;154:144-147.

15. Roza AM, Shizgal HM: The Harris-Benedict equation re-evaluated: Resting energy requirement and the body cell mass. Am J Clin Nutr 1984;40:168-182.

16. Feurer ID, Crosby LO, Mullen JL: Measured and predicted resting energy expenditure in clinically stable patients. Clin Nutr 1984;3:27. 31.

17. Quebbemann EJ, Ausman RK, Schecter TC: A re-evaluation of the energy expenditure during parenteral nutrition. Ann Surg 1982;195:282285.

From the Pulmonary Division, University of Medicine and Dentistry of New Jersey - School of Osteopathic Medicine, Stratford, NJ.

Reprint requests to Dr Morley, 301 S Central Plaza, Suite 3100, Stratford, NJ 08084-1504. 


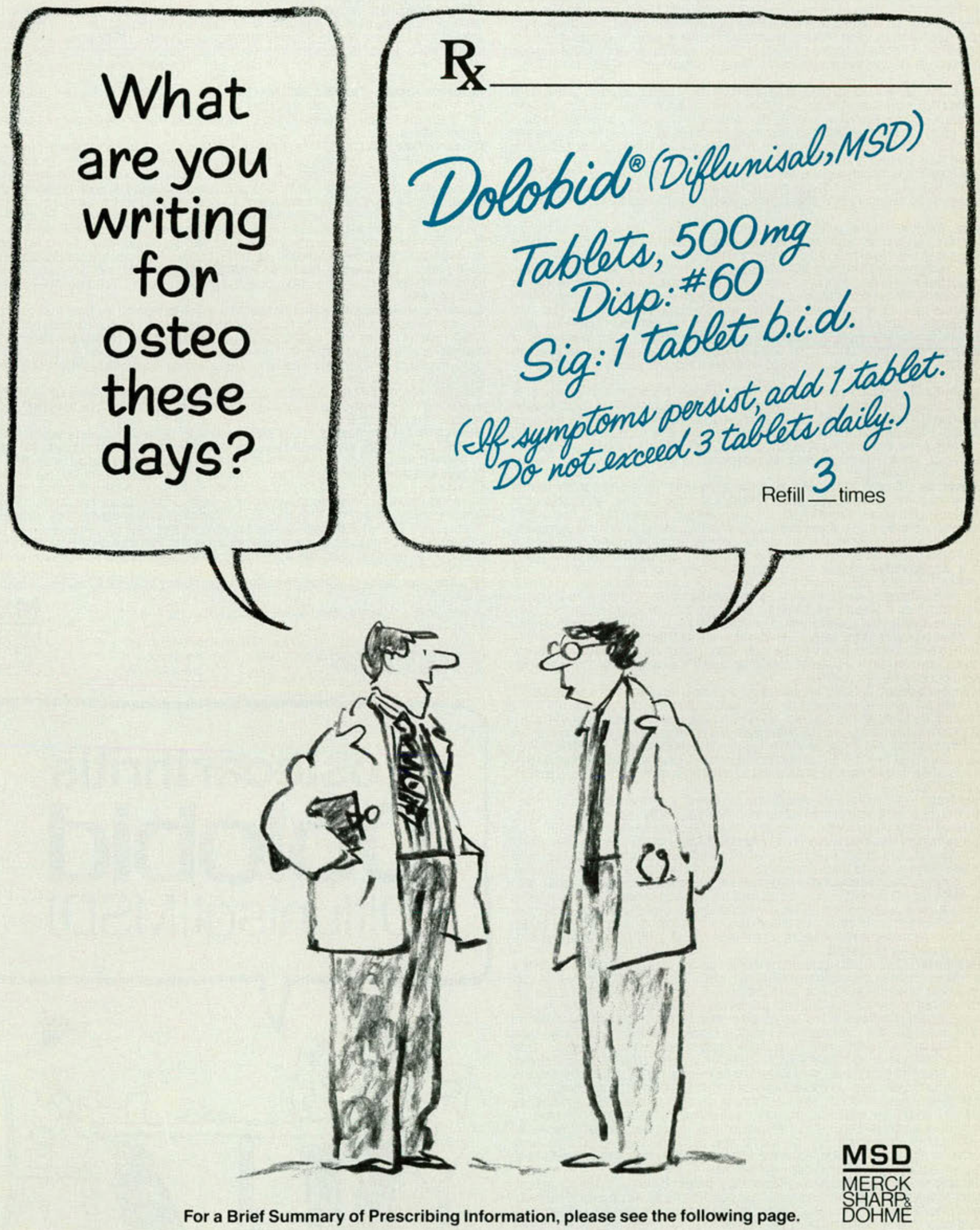


Contraindications: Hypersensitivity to this product, patients in whom acute asthmatic attacks, urtica ria, or rhinitis is precipitated by aspirin or other nonsteroidal anti-inflammatory drugs

Warnings: Peptic ulceration and gastrointestinal bleeding have been reported. Fatalities have occurre rarely. Gastrointestinal bleeding is associated with higher morbidity and mortality in patients acutely il with other conditions, the elderly, and patients with hemorrhagic disorders. In patients with active gastrointestinal bleeding or an active peptic ulcer, benefits of therapy with DOLOBID" (Diflunisal, MSO) must be weighed against possible hazards, an appropriate ulcer regimen should be instituted, ar progress carefully monitored; in patients with a history of upper or lower gastrointestinal tract disease, DOCOBID should be given only after consulting the ADVERSE REACTIONS section and under close

Risk of GI Ulcerations, Bleeding, and Perforation with NSAID Therapy: Serious gastrointestinal toxicity, such as bleeding, ulceration, and perforation, can occur at any time, with or without warning
symptoms, in patients treated chronically with NSAID therapy. Although minor upper gastrointestina problems, such as dyspepsia, are common, usually developing early in therapy, physicians should remain alert for ulceration and bleeding in patients treated chronically with NSAID seven in the absence of previous GI tract symptoms. In patients observed in clinical trials of several months to two years duration symptomatic upper GI ulcers, gross bleeding or perforation appear to occur in approximately $1 \%$ o inform patients about the signs and/or symptoms of serious GI toxicity and what steps to take if they

Studies to date have not identified any subset of patients not at risk of developing peptic ulceration and bleeding. Except for a prior history of serious Gl events and other risk factors known to be associated with peptic ulcer disease, such as alcoholism, smoking, elc. no risk factors (e. . . age, sex) have been assocated with increased risk Elderly or debilitated patients seem to tolerate ulceration or bleeding less well than other individuals and most spontaneous reports of fatal Gl events are in this population. Studies to date are inconclusive concerning the relative risk of various NSAIDs in causing such reactions. High doses of any NSAID probably carry a greater risk of these reactions, although controlled clinical trials mended dosage range), sufficient benefit should be anticipated to offset the potential increased risk of $G$ toxicity.

Precautions: General: Because serious GI tract ulceration and bleeding can occur without warning symptoms, physicians should follow chronically treated patients for the signs and symntoms of ulceratio and bleeding and should inform them of the importance of this follow-up (see WARNINGS: Risk of GI Ulcerations, Bleeding, and Perforation with NSAID Therapy). Although DOLOBID has less effect on platelet function and bleeding time than aspirin, at higher doses it is an inhibitor of platelet function; patient who may be adversely affected should be carefully observed. Because of reports of adverse eye finding with agents of this class, it is recommended that patients who develop eye complaints during treatmen have ophthalmologic studies. Peripheral edema has been observed; as with other drugs in this class DOLOBID should be used with caution in patients with compromised cardiac function, hypertension, drome; because diflunisal is a derivative of salicylic acid, the possibility of its association with Reye syndrome, because dilunisal is

Hypersensitivity Syndrome: A potentially lite-threatening, apparent hypersensitivity syndrome has been reported. This multisystem syndrome includes constitutional symptoms (fever, chills), and cutaneous findings (see ADVERSE REACTIONS, Dermatologic), and may also include involvernent of major organs (changes in liver function, jaundice, leukopenia, thrombocytopenia, eosinophilia, disseminate intravascular coagulation, renal impairment, including renal failure), and less specific findings (adenitis, arthralgia, myalgia, arthritis, malaise, anorexia, disorientation). If evidence of hypersensitivity occurs, DOLOBID should be discontinued.

Renal Effects: As with other nonsteroidal anti-inflammatory drugs, long-term administration of diflunisal to animals has resulted in renal papillary necrosis and other abnormal renal pathology. In humans, there have been reports of acute interstitial nephritis with hematuria and proteinuria and occasionally nephrotic syndrome. A second form of renal toxicity has been seen in patients with prerenal and renal conditions leading to a reduction in renal blood flow or blood volume, where renal prostaglandin have a supportive role in the maintenance of renal perfusion. In these patients, administration of an NSAID may cause a dose-dependent reduction in prostaglandin formation and may precipitate overt rena decompensation. Patients at greatest risk of this reaction are those with conditions such as renal o hepatic dysfunction, diabetes mellitus, advanced age, extracellular volume depletion from any cause, congestive heart failure, septicemia, pyelonephritis, or concomitant use of any nephrotoxic drug patient who may have reduced renal reserve. Discontinuation of NSAID therapy is typically followed by recovery to the pretreatment state. Since diflunisal is eliminated primarily by the kidneys, patients with significantly impaired renal function should be closely monitored, a lower daily dosage should be anticipated to avoid excessive drug accumulation.

Information for Patients: DOLOBID, like other drugs of its class, is not free of side effects and can cause discomfort and rarely more serious side effects such as gastrointestinal bleeding which may result in hospitalization and even fatal outcomes. NSAIDs (Non-Steroidal Anti-Inflammatory Drugs) are often essential agents in the management of arthritis butalso may be commonly employed for less serious conditions. Physicians may wish to discuss with their patients the potential risks (see WARNINGS, PRECAUTIONS, and ADVERSEREACTIONS) and likely benefits of NSAID treatment, particularly in less seripatient and physician.

Laboratory Tests: Liver Function Tests-As with other nonsteroidal anti-inflammatory drugs, borderline elevations of one or more liver tests may occur in up $1015 \%$ of patients. These abnormalities may progress, may remain essentially unchanged, or may be transient with continued therapy. The SGPT (ALT rest is probably the most sensitive indicator of liver dystunction. Meaningful ( 3 times the upper limit of normal) elevations of SGPT or SGOT (AST) occurred in controlled clinical trials in less than $1 \%$ o patients. A patient with symptoms and/or signs suggesting liver dysfunction, or in whom an abnormal
iver test has occurred, should be evaluated for evidence of the development of more severe hepatic reaciver test has occurred, should be evaluated for evidence of the development of more severe hepatic reacwith DOLOBID as well as with other nonsteroidal anti-inflammatory drugs. Although such reactions are rare, if abnormal liver tests persist or worsen, if clinical signs and symptoms consistent with liver disease develop. or if systemic manifestations occur (e.g., eosinophilia, rash, etc.), DOLOBID should be discontinued since liver reactions can be fatal.

Drug Interactions: DOLOBID prolongs prothrombin time in patients who are on oral anticoagulants. has not been shown to interact with tolbutamide but interacts with hydrochlorothiazide, furosemide, acelaminophen, aspirin, indomethacin, sulindac, and naproxen. Oral Anticoagulants - In some normal volunteers, concomitant administration of DOLOBID and warfarin, acenocoumarol, or phenprocoumon resulted in prolongation of prothrombin time. Accordingly, prothrombin time should be closely monitore during and for several days after concomitant administration; dosage of oral anticoagulants may require adjusiment. Tolbutamide - In diabetic patients, no significant effects were seen on tolbutamide plasma levels or fasting blood glucose. Hydrochlorothiazide - In normal volunteers, concomitant administration significantly increased the plasma levels and decreased the hyperuricemic effect of hydrochlorothiazide Furosemide - In normal volunteers, concomitant administration had no effect on the diuretic activity but decreased the hyperuricemic effect of furosemide. Antacids - Concomitant administration may reduce plasma levels of DOLOBID; this effect may be clinically significant when antacids are used on a continuous schedule. Acetaminophen - Concomitant administration in normal volunteers increased plasma levels of acetaminophen approximately $50 \%$ but had no effect on plasma levels of DOLOBID. Since acetaminophen in high doses has been associated with hepatotoxicity, concomitant administration

Drug Interactions: Nonsteroidal Anti-inflammatory Drugs: In normal volunteers on indo methacin, diflunisal decreased the renal clearance and significantly increased plasma levels of indomethacin; in some patients, such combined use was associated with fatal gastrointestinal hemorrhage. These drugs should not be used concomilantly. Salety and effectiveness of concomitant use with other nonstecan be made. The following information was obtained from studies in normal volunteers: Aspirin -A
small decrease in diflunisal levels with multiple concomitant doses; Sulindac-A lowering of plasma lev- els of active sulindac sulfide metabolite by approximately one third: Naproxen - No effect on plasma lev els of either drug, but significantly decreased urinary excretion of naproxen and its glucuronio Carcinogenesis, Mutagenesis, Impairment of Fertility: Diflunisal did not show carcinogen Pregnancy: Pregnancy Category C-DOLOBID* (Diflunisal, MSD) should be used during the first tw trimesters of pregnancy only if the potential henefit ustifies the potential risk to the fetus: because of th known effect of drugs of this class on the human felal cardiovascular system (closure of ductus arterio sus), use during the third trimester is not recommended

Nursing Mothers: Diflunisal is excreted in human milk in concentrations of $2 \%$ to $7 \%$ of those plasma. A decision should be made whether to discontinue nursing or to discontinue the drug, laking in account the importance of the drug to the mother.

Pediatric Use: Safety and effectiveness in infants and children have not been established, and use Children below 12 years of age is not recommended.

Adverse Reactions: The controlled clinical trials encompass observations in 2,427 patients. Liste below are the adverse reactions reported in the 1,314 patients who received treatment in studies of tw: weeks or longer. Of these patients, 513 were treated for at least 24 weeks, 255 for at least 48 weeks, and received short-term treatment for mild to moderate pain. The most frequent types of adverse reaction 0ccurring are gastrointestinal.

Incidence Greater than 1\%: Gastrointestinal-Nausea,* vomiting, dyspepsia,* gastrointestin pain," diarrhea,* constipation, flatulence. Psychiatric - Somnolence, insomnia. Central Nervous Sys tem-Dizziness. Special Senses-Tinnitus. Dermatologic-Rash.* Miscellaneous-Headache, Incidence Less than 1 in 100: The probability exists of a causal relationship between DOLOBID an these adverse reactions. Dermatologic - Erythema multiforme, exfoliative dermatitis, Stevens-Johnso syndrome, toxic epidermal necrolysis, urticaria, pruritus, sweating, dry mucous membranes, stomatitis photosensitivity, Gastrointestinal-Peptic ulcer, gastrointestinal bleeding, anorexia, eructation, gastroin hepatitis. Hematologic-Thrombocytopenia, agranulocytosis; hemolytic anemia. GenitourinaryDysuria; renal impairment, including renal failure; interstitial nephritis: hematuria: proteinuria Psychiatric-Nervousness, depression, hallucinations, confusion, disorientation. Centrai'Nervous Sys tem-Vertigo, light-headedness, paresthesias. Special Senses - Transient visual disturbances includin blurred vision. Hypersensitivity Reactions Acute anaphylactic reaction with bronchospasm; angio edema. Hypersensitivity vasculitis. Hypersensitivity syndrome (see PRECAUUTIONS). Miscellaneous-

Causal Relationship Unknown: Other reactions have been reported in clinical trials or since th drug was marketed but occurred under circumstances where a causal relationship could not be estab lished. However, in these rarely reported events, that possibility cannot be excluded. Therefore, thes observations are listed to serve as alerting information to physicians. Respiratory-Dyspnea. Cardiovas
cular-Palpitation, syncope. Musculoskeletal-Muscle cramps. Genitourinary-Nephrotic syndrome Miscellaneous-Chest pain

Potential Adverse Effects: In addition, a variety of adverse effects not observed with DOLOBID, bu reported with other nonsteroidal analgesic/anti-inflammatory agents, should be considered potentia

management of Overdosage: In the event of overdosage, the stomach should be emptied by induc ing vomiting or by gastric lavage, and the patient carefully observed and given symptomatic and support Dosage and Administration: For mild to moderate pain, an initial dose of $1000 \mathrm{mg}$ followed b $500 \mathrm{mg}$ every 8-12 hours is recommended for most patients. A lower dosage may be appropriate depend ing on such factors as pain severity, patient response, weight, or advanced age; for example, $500 \mathrm{mg}$ initially, followed by $250 \mathrm{mg}$ every $8-12$ hours. For osteoarthritis and rheumatoid arthritis, the suggested dosage range is $500 \mathrm{mg}$ to $1000 \mathrm{mg}$ daily in two divided doses; the dosage may be increased or decrease according to patient response. Maintenance doses higher than $1500 \mathrm{mg}$ a day are not recommendec DOLOBIO may be administered with water, milk, or meals. Tablets should be swallowed whole, no crushed or chewed.

How Supplied: Tablets, containing 250 or $500 \mathrm{mg}$, in unit-dose packages of 100 and unit-of-use bottle of 60

are not marked with an asterisk.

MSL

For more detailed information, consult your MSD Representative or see

Prescribing Information. Merck Sharp \& Dohme, Division of Merck \&
Co., AvC. West Point, PA 19486
J7DL 33 R3(724)

MERCK

$\mathrm{DOHME}$

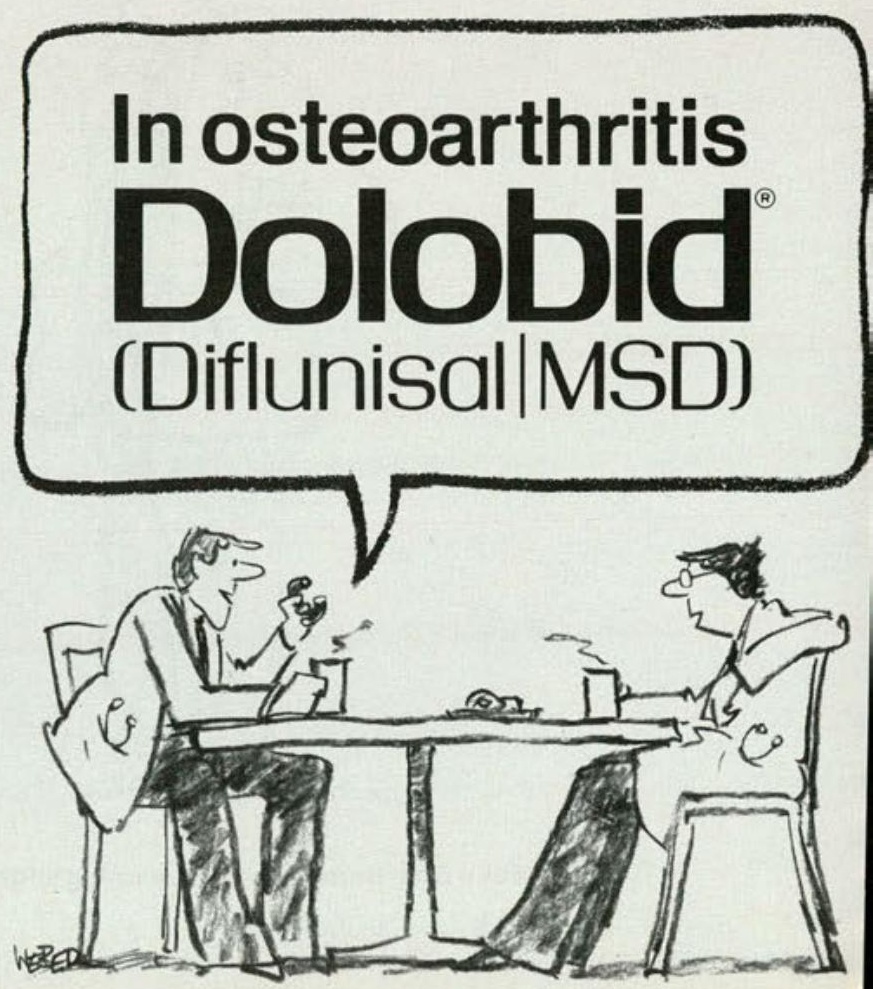

